\title{
Birthweight of the babies delivered by chronic energy deficient mothers in National Nutrition Program (NNP) intervention area
}

\author{
Karim $\mathrm{MR}^{1}$, Flora $\mathrm{MS}^{1}$, Akhter $\mathrm{S}^{2}$ \\ ${ }^{1}$ Department of Epidemiology, National Institute of Preventive and Social Medicine, Dhaka, \\ ${ }^{2}$ Combined Military Hospital, Dhaka Cantonment, Dhaka.
}

\begin{abstract}
An operational research was done to explore the effect of targeted food supplementation by comparing the birthweight of the babies of two areas (intervention \& nonintervention). This record-based study was carried out in Kapasia and Savar upazila of Dhaka division, relying on the primary organizational data of 565 mothers. In the National Nutrition Program (NNP) area only fifty percent moderate to severe malnourished [Chronic Energy Deficiency (CED) II \& III] mothers were preferably targeted for onsite food support while 34 of them managed to complete the full course. The mean $( \pm \mathrm{SD}) \mathrm{BMI}$ of the supplemented mothers were lower $(16.21 \pm 0.77) \mathrm{kg} / \mathrm{m}^{2}$, than non-supplemented mothers in Kapasia $(17.14 \pm .82) \mathrm{kg} / \mathrm{m}^{2}$ and Savar $\left.17.03 \pm 1.19\right) \mathrm{kg} / \mathrm{m}^{2}$ area. The mean $( \pm \mathrm{SD})$ birth-weight for non NNP (Savar) category Mean $( \pm$ SD) $2470 \pm 366.03$ grams, for NNP (Kapasia) non-supplemented group 2720.18 ( \pm 368.63$)$ grams and in Kapasia good supplemented group it was $2752.94( \pm 344.86)$ grams. Supplemented and non-supplemented mothers of NNP mothers were four times more likely to deliver normal birthweight babies [odds ratio with 95\%CI $3.84(2.01,7.34)$ ] and [odds ratio with 95\%CI 3.90 $(2.17,7.01)]$ than mothers of control area when adjusted for sociodemographic variables. Birth weight status improved with better CED levels. Birth weight adjusted for CED status, had no significant association with food supplementation. In this study, the basic findings were food supplementation could not increase birth-weight significantly as other effects contributed to improve birthweight were removed. As fully supplemented CED III mothers gave birth almost same weighted babies in comparison to the babies of CED I mothers; the recovery from the probability of being less weighted than the current status might be considered as a potential effect of food supplementation.
\end{abstract}

\section{Introduction}

Low birth weight is a major contributor to neonatal and postneonatal mortality. Twenty million infants worldwide, representing 15.5 per cent of all births, are born with low birthweight, 95.6 per cent of them in developing countries and almost 70 per cent of all low birthweight births occur in Asia, where perinatal and infant mortality is already high $^{1}$ and in Bangladesh the prevalence is forty percent $^{2}$.

In both developed and developing countries, birth weight is probably the single most important factor that effects neonatal mortality, postneonatal mortality and of infant and childhood morbidity. Kramer described 43 factors related to the infant, the mother or the physical environment and play an important role in determining the infant's birthweight and future health ${ }^{3}$. In the developing world, lacking proper health systems and resources, the level of maternal education may be of prime importance in the determination of health outcomes of mothers and their infants and children ${ }^{4}$.

There is an well-established relationship between lower birthweight (LBW) and decrease survival, increase morbidity, and higher risk of developing long-term chronic diseases of adults, such as hypertension, type 2 diabetes, and coronary heart disease $^{5,6}$. In other contexts, birth weight is an "input"-i.e., a proxy for the initial endowment of an infant's "health human capital". Consistent with this view, researcher found that LBW infants tend to have lower educational attainment, poorer selfreported health status, and reduced employment and earnings as adults, relative to their normal weight counterparts ${ }^{7}$.

The primary role of low birth weight and prematurity for peri-natal mortality and morbidity in developing countries and its association with 
under-nutrition and malnutrition in the mothers', had motivated the policy makers to employ various attempts to improve pregnancy outcome through food supplementation ${ }^{1}$. In May 2004, Copenhagen Consensus also declared that intervention addressing micronutrient deficiency and other dimensions of hunger and malnutrition are excellent investment ${ }^{8}$.

For at least 65 years, nutritionists, physicians, and public-health policy-makers have studied the impact of food supplementation to pregnant women who are under-nourished or otherwise at risk for adverse pregnancy outcomes ${ }^{9}$. Many observational studies found that pregnancy weight gain below the recommended range was associated with low birth weight and preterm birth and concluded that maternal weight gain strongly correlates with birth weight ${ }^{10}$. Kramer failed to provide evidence that undernourished women benefited more than those who were adequately nourished ${ }^{11}$. On the other hand the Gambian supplementation trial, which succeeded in reducing both stillbirth and neonatal death by providing a much higher net increase in energy intake in a rural setting had enlighten the positive effects of supplementation on birthweight if targeted genuinely and continued uninterruptedly ${ }^{12}$. Thus, pregnancy is one of the logical target periods for nutrition interventions, potentially providing combined opportunities to treat or prevent maternal depletion and undernutrition of the foetus ${ }^{13}$.

In National Nutrition Program; after disclosing her pregnancy status, regardless of BMI, a mother is weighed monthly until delivery when the birthweight of child is recorded. A woman who's BMI in early pregnancy is equal to or less than 18.5 are enrolled in a daily on-site supplementary feeding regimen which continues until delivery. The daily supplement contained $80 \mathrm{~g}$ roasted rice powder, $40 \mathrm{~g}$ roasted pulse powder, $20 \mathrm{~g}$ molasses, and $12 \mathrm{~mL}$ $(6 \mathrm{~g})$ soybean oil, which provided $608 \mathrm{kcal}$ and $17.9 \mathrm{~g}$ vegetable protein (11.5\% of total energy). The food supplement supports an estimated $27 \%$ of a woman's daily allowance for calories, using $2,280 \mathrm{kcal}$ as the daily requirement for pregnant women.

Several studies raised doubt about the efficiency of the Nutrition Program in correctly targeting food supplementation to pregnant women. It also showed that food supplementation neither leads to enhanced pregnancy weight gain nor does it provide any evidence of a reduction in prevalence of low birth weight ${ }^{14}$. But studies that put some rays of hope concluded that primigravidae receiving supplementations were more likely to have adequate pregnancy-related weight gain than the better-off non-supplemented primigravidae. The mean birth-weights of infants of the supplemented women with low BMI were comparable to those of the better-off, non supplemented women ${ }^{15}$.

There is no assurance that energy intake and subsequent weight gain were higher in the supplemented group than they would have been in the absence of the supplement ${ }^{15}$. Apart from her basic dietary intake during pregnancy period, other important factors that riddled us are the energy and nutrient composition of the supplement ${ }^{16}$, the timing and total duration of supplementation, the replacement level of the supplement ${ }^{17}$. Studies conducted to find out the impact of NNP on pregnancy outcome, found a gross under report of birthweight. It is assumed that women who received the supplement and had a low-birthweight infant did not have the birth-weight recorded, perhaps to avoid conveying bad news to the providers of the supplement and to the investigators ${ }^{18,19}$.

Recent studies raised queries about the efficiency of the National Nutrition Program in correctly targeting food supplementation to pregnant women thus enhancing pregnancy weight gain, reducing prevalence of low birth weight ${ }^{14}$. The results of the operational research might help the policy makers by exploring the facts of food supplementation strategy and its effects in terms maternal and fetal outcome and thus providing scopes for further modification and better implementation strategy of the National Nutrition Program.

\section{Materials and Methods}

This was a non-experimental operational research aiming to evaluate the effect of targeted food supplementation by NNP Bangladesh. The samples were taken from two different upazillas served by two different non-government national organizations. Voluntary Association for Rural Development (VARD) was implementing the maternal and child nutritional supportive program following NNP guidelines in Kapasia upazilla and nonNNP [Gonosashthaya Kendra] (GK) was delivering maternal \& Child health Care services through primary health care in Savar. Both the areas are about 20 to 30 kilometers from Dhaka and have almost same demographic composition.

At first 1193 mothers' information were collected, 658 from non NNP Gonosasthaya Kendra \& 535 from VARD NNP area all of whom delivered from $1^{\text {st }}$ January to $31^{\text {st }}$ December 2008 and were permanent resident of those areas. All of them were recorded either as chronic energy deficient mothers 
or gaining weight less than $1 \mathrm{~kg}$ per month. Following criteria of having BMI less than 18.5, delivered at term ,registered within 120 days of last menstrual period and birthweight recorded within 72 hours of delivery, 565 of 1193 were included in the study for analysis. Mothers with multiple pregnancies or suffering from chronic diseases were excluded from the study. Early pregnancy BMI, taken at registration time, was considered as baseline nutritional status (as a proxy for prepregnancy BMI) and last weight taken before delivery was considered as end-line BMI. Accordingly pregnancy weight gain was estimated.

Data collected from the records of Gonoshasthaya Kendra were overburdened by inconsistencies and missing values and only 126 of the sample mothers met the selection criteria. Records from NNP area revealed that 228 out of 439 chronic energy deficient mothers were not-supplemented. So the samples were primarily divided into three categories, Non NNP area (Gonoshasthaya Kendra Savar) $(\mathrm{n}=126), \quad \mathrm{NNP}$ area (Kapasia not supplemented) $(\mathrm{n}=228), \quad \mathrm{NNP}$ area (Kapasia supplemented) $(\mathrm{n}=211)$.

Duration of food supplementation varied from 1 to 160 days among NNP enrolled CED mothers. So those who were supplemented for fewer days and those who completed the full course of supplementation should be presented separately for better interpretation regarding the effects of supplementation on birth weight among different categories. Three supplementation groups were constructed comprising low, intermediate and high number of days of supplementation and were defined as no or 0 days, <120 (low) days, 120-159 (intermediate) days and $\geq 160$ (high) days of supplementation, respectively for registration month three. In registration month 4; no, low, intermediate and high supplementation groups were defined as 0 days, <100 days, 100-139 days and $\geq 140$ days, respectively. Researcher further segregated the Kapasia respondents as GKSavar samples were normally destitute of supplementation. So the classification for Kapasia was 'no supplementation $(\mathrm{n}=228)$ ', 'poor supplementation $\quad(n=112)$ ', 'moderate supplementation $\quad(n=65)$ ', 'good/adequate supplementation $(\mathrm{n}=35)$ ' (figure 1$)$.

Collected data were cleaned, edited, analyzed and interpreted with the help of the computer by SPSS 16.0 for windows.

\section{Results}

This record-based study was carried out to explore the effect of targeted food supplementation comparing the pregnancy weight gain of the sample mothers of NNP and non NNP areas. The mean age of the sample mothers was around 24 years among all categories. Illiteracy rate was higher in Savar area mothers $(21.4 \%)$ and fathers $(19.8 \%)$ than those of Kapasia. Occupational categories were also significantly different in the comparison groups. Almost all the kapasia sample mothers received ANC care for $\geq 4$ visit whereas one-third of Savar mothers did not. Male babies had on average better weight than female babies. Though sample size was small, a three dimentional bargraph shows better sensitivity of the male babies' birthweight to supplementation status as relating to early pregnancy BMI (Figure 1). Supplemented mothers from NNParea (Kapasia) had, on average, lower BMI $(16.21 \pm 0.77) \mathrm{kg} / \mathrm{m}^{2}$ than non supplemented mothers in NNParea (Kapasia) (17.14 .82) kg/m² and non NNP (Savar) $(17.03 \pm 1.19) \mathrm{kg} / \mathrm{m}^{2}$ area. More than $90 \%$ of supplemented mothers were at or below CED II level of malnutrition (table I).

There was significant relationship between food supplementation and birthweight $(\mathrm{p}=<0.001)$; on average nonNNP, Savar group babies were born with the lowest birthweight $(2470.44 \pm 366.04)$ gm whereas almost no difference was observed in birthweight between supplemented and nonsupplemented mothers of NNP area $(2664.15 \pm 360.33$ and $2720.18 \pm 368.63)$ gm. After adjusting for socio-demographic and early pregnancy BMI status, the relationship persisted (table II). Similar findings were observed when birthweight was categorized as low birthweight and normal (table III). After adjustment supplemented mothers were four times more likely to deliver normal birthweight babies [OR with $95 \%$ CI 3.84 $(2.01,7.34)]$ than mothers of control area and nonsupplemented mothers of NNP were also four times more likely to have targeted birthweight [OR with 95\% CI $3.90(2.17,7.01)]$.

Only eight percent of all eligible Kapasia pregnant mothers got full course of supplementation (figure 2 ). On the basis of duration of supplementation supplemented mothers were categorized into no poor, moderate and good supplementation. Good supplemented mothers delivered better weighted babies (2752.94 \pm 344.86$) \mathrm{gm}$ than all other subcategories based on duration of supplementation though not statistically significant. The birthweight status were compared among supplementation categories and found no association (table not shown, figure 3 ). 
Table I: Background Characteristics of Study Samples

\begin{tabular}{|c|c|c|c|c|c|c|c|}
\hline \multirow{3}{*}{$\begin{array}{l}\text { Background } \\
\text { Characteristics }\end{array}$} & \multicolumn{6}{|c|}{ NNP Area } & \multirow{3}{*}{$\mathrm{p}$-value } \\
\hline & \multicolumn{2}{|c|}{$\begin{array}{c}\text { Non NNP area } \\
\quad(n=126)\end{array}$} & \multicolumn{2}{|c|}{$\begin{array}{l}\text { Not supplemented } \\
(\mathrm{n}=228)\end{array}$} & \multicolumn{2}{|c|}{$\begin{array}{c}\text { Supplemented } \\
(\mathrm{n}=211)\end{array}$} & \\
\hline & $\mathrm{n}$ & $(\%)$ & $\mathrm{n}$ & $(\%)$ & $\mathrm{n}$ & $(\%)$ & \\
\hline \multicolumn{8}{|l|}{ Age of mothers in years } \\
\hline$\leq 19$ & 8 & $(6.3)$ & 29 & $(12.7)$ & 38 & $(18.0)$ & \multirow{5}{*}{$.006^{*}$} \\
\hline $20-24$ & 54 & $(42.9)$ & 98 & 43.1) & 84 & $(39.8)$ & \\
\hline $25-29$ & 50 & $(39.7)$ & 58 & $((25.4)$ & 51 & $(24.2)$ & \\
\hline $30-34$ & 10 & $(7.9)$ & 24 & $(10.5)$ & 26 & $(12.3)$ & \\
\hline$\geq 35$ & 4 & $(3.2)$ & 19 & $(8.3)$ & 12 & $(5.7)$ & \\
\hline \multicolumn{8}{|l|}{ Mothers education } \\
\hline No education & 27 & $(21.4)$ & 14 & $(6.1)$ & 15 & $(7.1)$ & \multirow{4}{*}{$<0.001 *$} \\
\hline$<$ Primary & 10 & $(7.9)$ & 48 & $(21.1)$ & 61 & $(28.9)$ & \\
\hline $5-9$ years & 78 & $(61.9)$ & 129 & $(56.6)$ & 108 & $(51.2)$ & \\
\hline SSC and above & 11 & $(8.8)$ & 37 & $(16.2)$ & 27 & (12.8) & \\
\hline \multicolumn{8}{|l|}{ Fathers' education } \\
\hline No education & 25 & $(19.8)$ & 27 & $(11.8)$ & 30 & $(14.2)$ & \multirow{4}{*}{$<0.001 *$} \\
\hline$<$ Primary & 14 & $(11.1)$ & 69 & $(25.9)$ & 72 & $(34.1)$ & \\
\hline $5-9$ years & 68 & $(54.0)$ & 105 & $(46.1)$ & 80 & $(37.9)$ & \\
\hline SSC and above & 19 & $(15.1)$ & 37 & $(16.2)$ & 29 & (13.7) & \\
\hline \multicolumn{8}{|l|}{ Fathers' occupation } \\
\hline Unemployed & 3 & $(2.4)$ & 7 & $(3.1)$ & 9 & $(4.3)$ & \multirow{5}{*}{$<0.001 *$} \\
\hline Heavy worker & 46 & $(36.5)$ & 103 & $(45.2)$ & 124 & $(58.8)$ & \\
\hline Skilled labour & 30 & $(23.8)$ & 21 & $(9.2)$ & 17 & $(8.1)$ & \\
\hline Businessman & 25 & $(19.8)$ & 64 & $(28.1)$ & 39 & $(18.5)$ & \\
\hline Serviceman & 22 & $(17.5)$ & 33 & $(14.5)$ & 22 & $(10.4)$ & \\
\hline \multicolumn{8}{|l|}{ ANC category } \\
\hline Less than four visit & 42 & $(33.3)$ & 7 & (3.1) & 5 & $(2.4)$ & \multirow[b]{2}{*}{$<0.001^{*}$} \\
\hline More than four visit & 84 & $(66.7)$ & 221 & $(97.5)$ & 206 & $(96.9)$ & \\
\hline \multicolumn{8}{|l|}{ Iron Supplement status } \\
\hline$<90$ days & 23 & $(8.6)$ & 131 & $(49.2)$ & 112 & $(42.1)$ & \multirow[t]{2}{*}{$<0.001$} \\
\hline$=>90$ days & 103 & $(34.4)$ & 97 & $(32.4)$ & 99 & $(33.1)$ & \\
\hline \multicolumn{8}{|l|}{ Weight of the baby } \\
\hline Female baby wt Mean \pm SD & \multicolumn{2}{|c|}{$2422.37 \pm 341.6$} & \multicolumn{2}{|c|}{$2679.81 \pm 365.34$} & \multicolumn{2}{|c|}{$2548.25 \pm 344.70$} & $<0.001$ \\
\hline M Male baby wt Mean \pm SD & \multicolumn{2}{|c|}{$2510.19 \pm 382.96$} & \multicolumn{2}{|c|}{$2754.03 \pm 369.44$} & \multicolumn{2}{|c|}{$2768.56 \pm 343.11$} & $<0.001$ \\
\hline \multicolumn{8}{|l|}{ CED categories } \\
\hline CED I & 78 & $(61.9)$ & 140 & $(61.4)$ & 14 & $(6.6)$ & \\
\hline CED II & 26 & $(20.6)$ & 72 & $(31.6)$ & 132 & $(62.6)$ & $<0.001 *$ \\
\hline CED III & 22 & (17.5) & 16 & $(7.0)$ & 65 & (30.8) & \\
\hline Mean \pm SD & 17. & .19 & & & & & $<0.001 * *$ \\
\hline
\end{tabular}

*p values obtained by $\chi^{2}$ test ; ** $\mathrm{p}$ value obtained by $\mathrm{F}$ test.

Table II Birthweight According to Supplementation Status

\begin{tabular}{|c|c|c|c|c|c|}
\hline \multirow[t]{2}{*}{ Supplement status } & \multicolumn{5}{|c|}{ Adjusted for other variables } \\
\hline & Mean \pm SD & $\mathrm{p}$ & $\beta$ & F change & $\mathrm{p}$ \\
\hline Non NNP area* & $2470.44 \pm 366.04$ & & .32 & & \\
\hline NNP Non-supplemented & $2720.18 \pm 368.63$ & $<0.001$ & .33 & 10.05 & $<0.001$ \\
\hline NNP Supplemented & $2664.15 \pm 360.33$ & & & & \\
\hline
\end{tabular}

* Reference category. Non NNP area

Table III: Birthweight category by supplementation status

\begin{tabular}{|c|c|c|c|c|c|}
\hline \multirow[t]{2}{*}{ Supplement status } & \multicolumn{5}{|c|}{ Birth weight category } \\
\hline & $<2500 \mathrm{~g}$ & $2500 \mathrm{~g}$ & $\mathrm{p}$ & Crude OR[95\%CI] & Adjusted OR $[95 \% \mathrm{CI}]$ \\
\hline & $\mathrm{N}(\%)$ & $\mathrm{N}(\%)$ & & & \\
\hline Non NNP area* & $62(49.2)$ & $64(50.8)$ & & & \\
\hline NNP Non-supplemented* & $37(16.2)$ & $191(83.8)$ & $<0.001$ & $5.00(3.05,8.21)$ & $3.90(2.17,7.01)$ \\
\hline NNP Supplemented & $49(23.2)$ & $162(76.8)$ & & $3.20(1.99,5.14)$ & $3.84(2.01,7.34)$ \\
\hline
\end{tabular}

$*$ Reference category $=$ Non NNP area $\quad \mathrm{CI}=$ Confidence Interval 


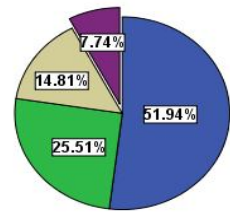

Figure 1. NNP supplementation category based on duration of supplementation

NNP supplemented category were subdivided into poor, moderate and good
supplementation categories comprising low, intermediate and high number supplementation which equated to $<120$ (poor) days, $120-159$ (moderate) days and $\geq 160$ (good) days of supplementation for registration month 3 , respectively. In registration mont days and 2140 days, respectively.
daser,
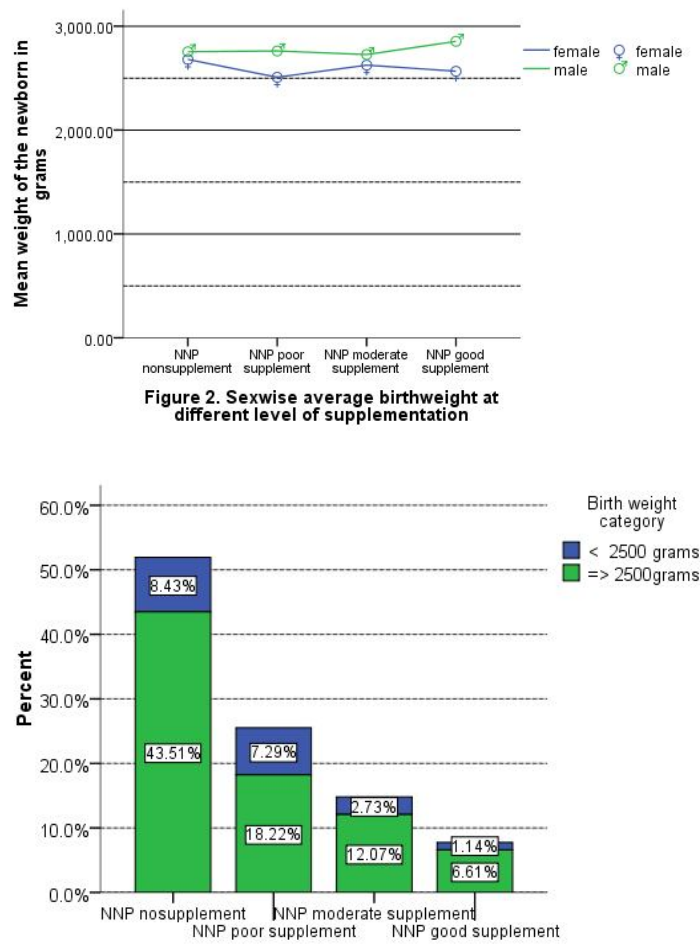

Figure 3. Bithweight status at different level of supplementation in NNP area

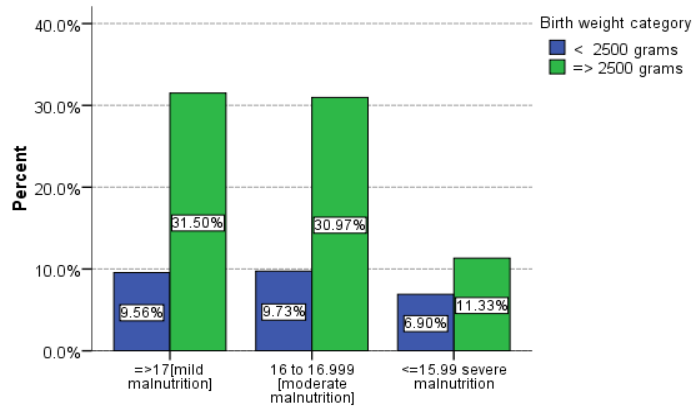

Figure 4. Birthweight status among Chronic Energy
Deficiency categories in NNP area

\section{Discussion}

This study was performed to assess the effects of pregnancy interventions through nutrition project, using project-based data.

Most of the factors that might influence the birthweight were matched prior analysis (socioeconomic condition, co-morbidity, multiple pregnancies). Some other factors such as parity, ANC status, iron supplement status were found not significant by multivariate analysis. Mean birthweight of the nonNNP area significantly differed from NNP area and both NNP category (supplemented and not supplemented) mothers were four times more likely to have targeted birthweight than nonNNP samples. This was because of the fact that, the formats used for data recording and the workers involved with the data collection procedure of two organizations were dissimilar (in terms of training, experience and education). The logistics were also different (some used bathroom scale and others used UNI scale). Monitoring and data quality checking were also not uniform for two organizations. So for avoiding bias (inter-observer, measurement) researcher restricts the analysis with NNP data (Kapasia) alone. As Kapasia samples comprise both supplement and no supplement category so comparison between these categories would certainly reflects real effects of NNP provided food supplementation on birthweight (Sociodemographic and service related confounders matched inherently).

In this study, only eight percent of the $439 \mathrm{NNP}$ eligible mothers managed to complete the full course of onsite supplementation support. This result highlights serious deficiencies in the implementation of the NNP in these rural areas with over $50 \%$ of women either not receiving supplementation or receiving it incorrectly. In addition, those receiving food supplementation, nearly half started late and only about one in ten women received the full supplementation ${ }^{14,20}$.This study also showed that supplementation had an insignificant effect on birth weight, in keeping with some studies ${ }^{21-26}$, while other studies have reported a significant impact of supplementation on birth weight $^{11,16,27-30}$. The most recent food supplementation trial on undernourished women from the Gambia ${ }^{11}$ reported considerably larger effects on birth weight. The difference may be explained by the much higher energy [4258 kJ $(1017 \mathrm{kcal})]$ and protein content $(22 \mathrm{~g})$ of the Gambian supplement compared with that used in Bangladesh [2512 kJ (600 kcal) and 8.0-9.4 g, respectively].

The food supplementation in the NNP may be a replacement not a supplement, that $30 \%$ of the 
women substituted at least part of their domestic food intake by NNP food supplements ${ }^{31}$. Supplementation had a larger effect in undernourished women but the increment in birth weight due to supplementation was not evident in those women who were undernourished prior to or during pregnancy ${ }^{3}$. Several researchers have argued that the degree of maternal undernutrition may affect the response to supplementation ${ }^{32,33}$. The explanation may be when seriously malnourished women are supplemented they cannot 'afford' to direct the energy to the fetus. A WHO collaborative study $^{34}$ showed that weight gain of $1.5 \mathrm{~kg} /$ month during the last two trimesters is consistent with good pregnancy outcomes. However, the average monthly weight gain in the present study was considerably lower, averaging only $0.92 \mathrm{~kg} / \mathrm{month}$ in the second and third trimesters. The results of the present study also show that although severely malnourished women gained significantly more weight in pregnancy, they had a higher proportion of LBW babies compared with mild malnourished women (figure 4).

As it was a record based study, potential limitation was reliance on reported anthropometric measurement, height of the mothers and weight of the mothers. We relied on the records as the likelihood that any biases which continue to exist (e.g. from faulty weighing scales, recording errors, or intentional misrepresentation) would equally affect the data on the supplemented and nonsupplemented women.

\section{Conclusion}

Supplementation could not increase birth-weight significantly as other effects contributed to improve birth-weight were removed. As fully supplemented CED III mothers gave birth almost same weighted babies in comparison to the babies of CED I mothers; the recovery from being less weighted to the current status might be considered as a potential effect of food supplementation.

A large-scale well-designed trial is recommended to explore the effect of NNP food supplementation program on birthweight.

\section{References}

1. United Nations Children's Fund and World Health Organization, Low Birthweight: Country, regional and global estimates. UNICEF, New York, 2004.

2. Integrated Regional Information Networks (IRIN), Bangladesh: Children and women suffer severe malnutrition, 19 November 2008. Online. UNHCR Refworld, available at:http://www.unhcr.org/refworld/ docid/49267b141e.html [accessed 15 April 2009].
3. Kramer M. S. Determinants of low birth weight: methodological assessment and meta-analysis, Bulletin of the World Health Organization 1987; 65 (5): 663-737.

4. Muthayyas S. Division of Nutrition, St. John's Medical College \& Research Institute, St. John's National Academy of Health Sciences, Bangalore, India Maternal nutrition \& low birth weight - what is really important? Indian J Med Res 130, November 2009; 600-608.

5. McCormick M. The contribution of low birth weight to infant mortality and childhood morbidity. N Engl J Med. 1985;312:82-90.

6. Barker DJP. Mothers, babies and health in later life. Edinburgh: Livingstone 1998;217 p.

7. Behrman JR, Rosenzweig MR, Taubman P. Endowments and the allocations of schooling in the family and in the marriage market: The Twins experiment. Journal of political economy 1994; 102: 1131-74.

8. Alderman H, Behrman JR and Hoddinott J. Economic and nutritional analyses offer substantial synergies for understanding human nutrition. World Bank, Africa Region, Washington, DC 20433; Population Studies Center, University of Pennsylvania, Philadelphia, PA 19104-6297; and International Food Policy Research Institute (IFPRI), Washington, DC 20006

9. Rush D. Maternal nutrition and perinatal survival. J Health Popul Nutr. 2001; 19:S217-64.

10. Panahandeh Z. Gestational Weight Gain and Fetal BirthWeight in Rural Regions of Rasht: Iran. J Pediatr 2009; 19 (1): 18-24.

11. Ceesay SM, Prentice AM, Cole TJ, Foord F, Weaver LT, Poskitt EME at el. Effects on birth weight and perinatal mortality of maternal dietary supplements in rural Gambia: 5 year randomised controlled trial. BMJ 1997;315:786-90.

12. Villar J, \& Rivera J. Nutritional Supplementation During Two Consecutive Pregnancies and the Interim Lactation Period: Effect on Birthweight. Pediatrics. 1988; 81(1):51-57.

13. Editorial. Breaking the Cycles of Malnutrition: Are Pregnancy Nutrition Interventions Effective? J Health Popul Nutr 2001; 19(3):158-159.

14. Nahar S, Nicholas Mascie-Taylor and Begum HA. Impact of targeted food supplementation on pregnancy weight gain and birth weight in rural Bangladesh: an assessment of the Bangladesh Integrated Nutrition Program (BINP). Public Health Nutrition 2009; 12 (8): 1205-12

15. Ortolano SE, Mahmud Z, Kabir AFMI, Levinson FJ. Effect of Targeted Food Supplementation and Services in the Bangladesh Integrated Nutrition Project on Women and Their Pregnancy Outcomes. J Health Popul Nutr. 2003; 21: 83-9.

16. Kaseb F, Kimiagar M, Ghafarpoor M, Valaii N. Effect of traditional food supplementation during pregnancy on maternal weight gain and birthweight. Int J Vitam Nutr Res. 2002; 72(6): 389-93. 
17. Rich-Edwards J, Krieger N, Majzoub J, Zierler S, Lieberman E, Gilman M. Maternal experiences of racism and violence as predictors of preterm birth: rationale and study design. Paediatr Perinat Epidemiol. 2001;15(Suppl): 124-35

18. Kleinman JC. Maternal weight gain during pregnancy: determinants and consequences. Hyattsville, MD: National Center for Health Statistics, Public Health Service, 1990; p 24 (NCHS working paper series no. 33).

19. Schieve LA, Cogswell ME, Scanlon KS, Perry G, Ferre C, Blackmore-Prince $\mathrm{C}$ et al. Prepregnancy body mass index and pregnancy weight gain: associations with preterm delivery. Obstet Gynecol. 2000;96:194-200.

20. The World Bank (2005) Maintaining Momentum to 2015? An Impact Evaluation of Interventions to Improve Maternal and Child Health and Nutrition in Bangladesh. Washington, DC: World Bank.

21. Kardjati S, Kusin JA \& de With C, Energy supplementation in the last trimester of pregnancy in EastJava: I. Effect on birthweight. Br J Obstet Gynaecol. 1988; 95: 783-794.

22. Adair L \& Popkin BM, Birth weight, maturity and proportionality in Filipino infants. Hum Biol. 1988; 60: 319-339.

23. Alam DS, Yunus M, Axix KMA \& Francisco A, Birth weight and its association with maternal nutrition and socioeconomic variables in rural Bangladesh. Glimpse. 1998; 20: 3-4.

24. Rush D A randomized controlled trial of perinatal nutrition supplementation. Pediatrics. 1980; 65:683697.

25. Viegas OA, Scott PH, Cole TJ, Eaton P, Needham PG $\&$ Wharton BA. Dietary protein energy supplementation of pregnant Asian mothers at
Sorrento, Birmingham. II: Selective during third trimester only. Br Med J. 1982; 285:592-595.

26. Agarwal KN, Agarwal DK, Agarwal A, Rai S, Prasad R, Agarwal S \& Singh TB, Impact of the integrated child development services (ICDS) on maternal nutrition and birth weight in rural Varanasi. Indian Pediatr. 2000; 37: 1321-1327.

27. Lechtig A, Effect of food supplementation during pregnancy on birth weight. Pediatrics 1975; 56:508520 .

28. Prentice AM, Cole T, Ford F, Lamb W \& Whitehead $\mathrm{R}$, Increased birth weight after prenatal dietary supplementation of rural African women. Am J Clin Nutr. 1987; 46: 912-925.

29. Tontisirin K, Booranasubkajorn U, Hongsumarn A \& Thewtong D, Formulation and evaluation ofsupplementary foods for Thai pregnant women. Am J Clin Nutr. 1986; 43: 931-939.

30. Begum N, Hussain T, Afrid B \& Hamid A. Effectof supplementary feeding of pregnant women on birth weight of the newborn. Plant Foods Hum Nutr. 1991;41:329-336.

31. Abdullah M, Karim R \& Samad QA. Is the supplement a substitute or true supplementation to the usual diet?. In Results from the BINP Operations Research Dhaka: International Centre for Diarrhoeal Disease Research, Bangladesh. 2000; Project vol.2:p9

32. Pelto G, Dickin K \& Engle PA. Critical Link: Interventions for Physical Growth and Psychological Development: A Review. WHO/CHS/CAH/99.3. Geneva: Department of Child and Adolescent Health and Development, WHO. 1999.

33. Olson R. Developing Indicators that Predict Benefit from Prenatal Energy Supplementation. New York: Cornell University Plenum Press 1994; 241-262, 206. 